\title{
A CULTURA ESCOLAR E AS ESPECIFICIDADES DOS CURRÍCULOS OCULTOS
}

\section{A SCHOOL CULTURE AND SPECIFICITIES OF HIDDEN CURRICULUM}

\author{
Fernando Xavier Silva ${ }^{1}$ \\ Universidade Federal de São Carlos
}

\begin{abstract}
Resumo: Neste trabalho versou-se sobre a dimensão significante da escola e suas consequências para a formação de crianças e adolescentes, os quais, a partir dessa passagem em suas vivências, ingressarão na esfera pública passando pelo crivo da legitimidade do currículo escolar e seus valores socialmente fundados. O processo de escolarização e suas consequências para a formação de indivíduos deve ser explorada inicialmente pela construção ou/e desconstrução do(s) conceito(s) de cultura e suas implicações para a formação de uma possível concepção de cultura escolar. Essa particularidade escolar existe na acepção de inúmeros autores, dentre eles Pérez-Gómez, mas assume outra face nas ideias de Félix Guattari, que afirma ser a escola apenas uma instituição pela qual perpassa uma cultura capitalística a qual atinge todos os âmbitos da existência, para tudo que produz semiótica. Considerou-se também para a discussão o conceito de habitus de Pierre Bourdieu. Para tanto, o conceito de cultura foi discutido, assim como suas implicações para a formação de uma possível cultura escolar. As questões que nortearam este trabalho foram: a) essa especificidade cultural existe e quais as conseqüências para sua interrelação com a cultura ou as "culturas" que estão além dos muros? b) Qual a especificidade do ambiente escolar e por que "culturas" é atravessado? c) o currículo invisível, segundo a acepção de Perez, incide sobre a especificidade cultural escolar ou é apenas uma variável da simbiose escola-contexto macroestrutural, em especial a nova ordem neoliberal? d) como se formam novos habitus através da intervenção neoliberal? Palavras-chave: Cultura escolar; Habitus; Currículo Oculto.
\end{abstract}

\begin{abstract}
This paper focused on the significant dimension of the school and its consequences for the formation of children and adolescents, who, from this passage in their experiences, will enter the public sphere through the screening of the legitimacy of the school curriculum and its socially founded values. . The process of schooling and its consequences for the formation of individuals should be initially explored by the construction or / and deconstruction of the concept (s) of culture and its implications for the formation of a possible conception of school culture. This school particularity exists in the sense of many authors, among them Pérez-Gómez, but takes another face in the ideas of Félix Guattari, who claims that school is just an institution through which a capitalistic culture permeates all areas of existence, to everything that produces semiotics. It was also considered for discussion the concept of habitus of Pierre Bourdieu. To this end, the concept of culture was discussed, as well as its implications for the formation of a possible school culture. The questions that guided this work were: a) does this cultural specificity exist and what are the consequences for its interrelation with culture or the "cultures" that are beyond the walls? b) What is the specificity of the school environment and why are "cultures" crossed? c) Does the invisible curriculum, according to Perez's meaning, focus on school cultural specificity or is it just a variable of the macrostructural school-context symbiosis, especially the new neoliberal order? d) How do new
\end{abstract}

${ }^{1}$ ORCID: http://orcid.org/0000-0001-7379-8541. EMAIL: fernando_xs@hotmail.com.

Revista Tópicos Educacionais, Pernambuco, v. 27, n. 01, p. 195-209, 2021. ISSN: 2448-0215.

https://periodicos.ufpe.br/revistas/topicoseducacionais/index 


\section{Revista Tópicos Educacionais}

habitus form through neoliberal intervention? Keywords: Habitus, Hidden Curriculum, School culture

Keywords: Coronavirus; Basic Education; Public policies; Social vulnerability; Symbolic violence

\section{INTRODUÇÃO}

Na busca pela compreensão da linha tênue que em tese tornaria diferente a cultura escolar das outras circuncidantes, discutiu-se a seguir como essa particularidade aparece em muitos autores. A primeira seção apresenta uma reflexão sobre o conceito de cultura, sem a pretensão de analisar o termo exaustivamente preparou-se o terreno no qual foi discutida a noção de que a escola é um espaço onde há um entrecruzamento de culturas (Gomes, 2001, p. 21). O propósito foi o de buscarse a apreensão da relação das funções sociais da escola com o contexto neoliberal e suas implicações para a formação de habitus não criado unilateralmente pela instituição escolar, mas também pelos outros âmbitos da reprodução existencial.

\section{A NOÇÃO DE CULTURA}

A ideia do conceito de cultura como uma rede de significados transmitidos historicamente por diversos meios de socialização, dentre eles a família, a escola, a comunidade e as mídias foi trabalhada por Geertz (1989) que entendeu essa conformação como formas simbólicas constituindo redes onde os homens e as mulheres baseiam suas existências, onde seus atos fazem sentido a partir da localização numa teia de significados socialmente legitimados (GEERTZ, 1989).

O conceito de cultura, assim como todos os conceitos, é construído e desconstruído constantemente, não sendo possível fixá-lo como um axioma. Não é isento da própria interferência que a cultura pode acarretar na configuração desse termo. Em 1958 Tylor o definiu como "um todo complexo que inclui conhecimentos, crenças, arte, moral, leis, costumes ou qualquer outra capacidade ou hábitos adquiridos pelo homem como membro de uma sociedade" (TYLOR, 1981, p. 8).

O conceito então viria atrelado com parâmetros de cultura, as nações ocidentais seriam mais complexas ao terem supostamente acumulado mais desses elementos citados pelo autor, tomandose como superiores aos povos africanos e ameríndios, os quais teriam que passar por diversos estágios evolutivos para alcançarem tamanha complexidade. O uso do conceito como meio de exercício do etnocentrismo viria respaldado por outras áreas da ciência além da antropologia, como a biologia e as ciências médicas, que realizariam diversos experimentos buscando comprovar a hipótese de que a cultura "inferior" dos primitivos derivava também da insuficiência de estrutura Revista Tópicos Educacionais, Pernambuco, v. 27, n. 01, p. 195-209, 2021. ISSN: 2448-0215. https://periodicos.ufpe.br/revistas/topicoseducacionais/index DOI: $10.51359 / 2448-0215.2021 .249424$ 
física corporal para complexificar as suas relações sociais. Nesse ínterim, caixas cranianas e maxilares eram medidos e comparados aos de ocidentais.

O conceito foi reformulado e ressignificado a partir das comprovações de que as diferenças corporais não interferiam na complexidade social dos povos colonizados. E, além disso, alguns autores contraporiam veementemente a ideia de que as diversas culturas representariam estágios numa linha evolutiva. Dentre eles podemos citar Strauss (1976), que em seu artigo Raça e história problematiza a concepção de que haveria um só caminho para as culturas evoluírem. O autor afirma que não há razões ou provas concretas de que o progresso cultural deva ser entendido como virtude de tais e quais nações visto que as culturas se desenvolvem exatamente quando entram em contato com outras:

\begin{abstract}
Não estaremos perante um estranho paradoxo? Tomando os termos no sentido de que lhes atribuímos, vimos que todo o progresso cultural é função de uma coligação entre as culturas. Esta coligação consiste no pôr em comum (consciente ou inconsciente, voluntário ou involuntário, intencional ou acidental, procurado ou obrigado) das possibilidades que cada cultura encontra no seu desenvolvimento histórico; finalmente admitimos que esta coligação era tanto mais fecunda quanto se estabelecia entre culturas mais diversificadas (STRAUSS, 1976. p.23).
\end{abstract}

O conceito tomou outros rumos, tanto no senso comum quanto na literatura e no meio acadêmico. Cultura passou a ser sinônimo de status, uma atividade nobre que diferenciaria as classes sociais a partir de seus hábitos. Conforme Eagleton (2005), esse termo que é sinônimo de cultivo da terra $^{2}$ é confundido com refinamento, autocultura, indicando supostamente graus de realização da potencialidade do eu, individualizando o que é produzido socialmente. Nesse caso, também é cultivo, mas do individuo, que está indissociavelmente localizado em um período histórico especifico, em um meio social onde a trama de significados é a condição para que determinadas ações façam sentido. Por isso, tomar sopa antes das refeições, como é costume em muitas partes do Japão pode não fazer sentido no Brasil.

Porém, essa separação de um elemento da cultura é um erro cometido por diversos autores, dentre eles, Ruth Benedict em o Crisântemo e a Espada (1946), pois esse elemento não pode ser interpretado isoladamente, nem sua constituição não pode ser desconectada da totalidade de signos

\footnotetext{
${ }^{2}$ No Dicionário completo da Lingua Portuguesa Editora Melhoramentos ( 1992) o termo está definido como: 1) Ação, efeito, arte ou maneira de cultivar a terraou certas plantas. 2)Terreno cultivado 3) Bio. Propagação de microogarnismos ou cultivação de tecido vivo em um meio nutritivo preparado. 4. Bio. Produto de tal cultivação. 5)Aplicação do espírito a alguma coisa; estudo 6. Adiantamento, civilização. 7)Apuro, esmero, elegância.

Revista Tópicos Educacionais, Pernambuco, v. 27, n. 01, p. 195-209, 2021. ISSN: 2448-0215.
}

https://periodicos.ufpe.br/revistas/topicoseducacionais/index DOI: 10.51359/2448-0215.2021.249424 


\section{Revista Tópicos Educacionais}

daquela cultura. A autora citada tornou exótico o que era comum para os nativos, para os praticantes de tais hábitos, e o seu erro foi não considerar a cultura como algo que não pode ser ahistórico e que perpassa todos os âmbitos da vida, do pensamento à ação, do hábito de se casar em certa idade ao de cozinhar de certa maneira. Os indivíduos podem transgredir certos hábitos culturais, mas eles serão sempre referência para outros, mesmo que de forma negativa, pois o sentido do conjunto de signos legitimados é socializado pelas diversas instituições, e essa reprodução é que possibilita certa garantia de manutenção de configurações sociais. As transgressões existem, mas convivem com os hábitos estabelecidos em busca da hegemonia, através da qual podem tornar-se novos constituintes da trama de significados legitimada socialmente.

O conceito de cultura escolar em Gómes (2001) traz a compreensão da relação da escolarização com a configuração contemporânea da acumulação do capital. Discutiu-se a seguir uma possível especificidade da instituição escolar a ponto de formar uma cultura própria que se diferenciaria das externas por conta de suas formas de produção e reprodução de semióticas supostamente singulares.

\section{A ESTRUTURA ESCOLAR}

Antônio Candido, em sua obra A estrutura da escola (1956), sugere que os cientistas sociais optimizem as investigações acerca da instituição escolar a partir da constatação de que ela possui uma dinâmica própria. Sua estrutura administrativa é regida pelo poder público, mas ela seria apenas um dos componentes da estrutura total da escola, na qual o autor inclui uma vida social interna singular, pois constitutiva de relações especificas oriundas do contexto escolar (CANDIDO, 1956, p. 106). Com isso a estrutura administrativa de uma escola

exprime a sua organização no plano consciente, e corresponde a uma ordenação racional, deliberada pelo Poder Público. A estrutura total de uma escola é, todavia, algo mais amplo, compreendendo não apenas as relações ordenadas conscientemente, mas ainda todas as que derivam da sua existência enquanto grupo social. (CANDIDO, 1974, p. 107).

A interação e a cooperação entre os membros da escola produziria normas e regras que, não obstante as derivadas de outros grupos externos à escola produziria formações especificas a partir da própria sociabilidade construída internamente. Um exemplo dessa especificidade é o fato de que a sociabilidade interna é regida por uma dupla corrente: a que envolve o "ajustamento do imaturo aos padrões do adulto e a que exprime as suas necessidades e tendências ao mundo adulto" 
(CANDIDO, 1974, p.115). A prática pedagógica seria mais "satisfatória quanto melhor conseguisse atenuar a tensão das duas correntes" (CANDIDO, 1974, p.118) Esse fator idade seria uma variável importante na análise do contexto escolar, porque o grupo dos professores possuiria uma experiência de cultura representante dos padrões dominantes.

A instituição escolar tenta tolher os elementos pessoais do educador, as aulas são o ponto de encontro entre a sociabilidade do imaturo com a ordenação racional do Legislador (CANDIDO, 1974, p. 125)

Dayrel (1996) é outro autor que se volta para investigar as relações entre os educandos e os professores e os conflitos decorrentes das relações entre ambos. Também estuda as construções de identidades e a conformação de elementos constituintes da escola e suas funções na manutenção do status-quo escolar. O autor afirma que essa instituição, assim como vários espaços de convívio do aluno, é polissêmica, sendo assim, dentro da gama de horas disponíveis para os indivíduos produzirem sua própria identidade, a escola se configura como apenas mais um espaço público onde o encontro de elementos culturais distintos podem ser adquiridos, transformados ou reproduzidos. Por outro lado, a escola seria um dos poucos espaços públicos dedicados à reflexão e ampliação dos projetos individuais dos alunos. Como afirmou Dayrel (1996), a escola tenta sufocar a prática da relação inter-subjetiva. Tenta, mas em vão, porque há trangressões. A ressignificação do espaço escolar pelos próprios estudantes vem de encontro a toda uma bibliografia que afirmava o caráter quase inescapável da capacidade de formação do individuo pela estrutura. As transgressões descritas e analisadas por Dayrel (1996) permitem a constatação de que a escola não é apenas resultado de estruturas externas localizadas fora dos muros escolares, mas também produz hábitos, transgressões e modos de resolução de conflitos, espaços de superação de tramas estruturais não considerados por aqueles autores estruturalistas. ${ }^{3}$

A escola aparece como um espaço físico e simbólico que é constantemente modificado, reconstruído e ressignificado. O papel social hegemônico atribuído à escola no âmbito do senso comum parece ser o de tornar as crianças e os adolescentes côncios de seus papéis na polis, serem cidadãos participando ativamente da política, essa tomada como conceito amplo perpassando todos os âmbitos do mundo da vida (DAYREL, 1996).

Outra função seria a de ingressar as crianças e os adolescentes no mercado de trabalho. Este caráter utilitarista não deve ser descartado. Aliás, o conteúdo que é repassado nas escolas é uma

\footnotetext{
${ }^{3}$ Nos referimos aqui principalmente aos livros de Louis Althusser (1998) e Michel Foucault (2001). Revista Tópicos Educacionais, Pernambuco, v. 27, n. 01, p. 195-209, 2021. ISSN: 2448-0215. https://periodicos.ufpe.br/revistas/topicoseducacionais/index DOI: 10.51359/2448-0215.2021.249424 


\section{Revista Tópicos Educacionais}

Revista do Programa de Pós-Graduação em Educação

da Universidade Federal de Pernambuco (UFPE)

ferramenta ainda para a ascensão social, a escola não deve sufocar a potencialidade das relações que acontecem em seu interior, o aluno reduzido a sujeito cognoscente de forma mecânica pode não condizer com o que os curriculistas humanistas almejam, mas reflete o indivíduo esperado pelos elaboradores de políticas publicas que apenas são influenciados pelos papeis sociais construídos pela sociedade, que nesse momento vive uma construção de significados predominantemente orientados pela lógica do mercado, como veremos em outra parte desse texto.

Porém, Dayrel (1996) não teoriza a escola como o faz Candido (1971), pois este busca estruturas presentes em todas as escolas e Dayrel (1996) apresenta um estudo de caso descrevendo o conteúdo e a forma do cotidiano da escola estudada, mas não discute se ela pode ser considerada um tipo ideal pra outras escolas ou para todas as outras escolas públicas. A metodologia para tornar a escola apresentada como uma representação das outras não é trabalhada. Desse modo, Dayrel (1996) não considera também as espeficidades de cada escola, de cada bairro e de cada comunidade e ainda não atenta para as influencias das classes sociais, como o faz, por exemplo, Bourdieu (2005).

Estabelecer o limite da linha tênue que divide a liberdade de construção da autoimagem pelo aluno e sua construção heterodeterminada pelo professor ou pelos outros funcionários da escola é tarefa instigante, e pode ser buscada através da pesquisa empírica aliada a uma teorização que fundamente qualitativamente os conceitos de forma a não os solidificar em concepções consolidadas.

Gomez (2001) discutiu a escolarização de modo geral e também considera, assim como Dayrel (1996) e Candido (1971), a escola como ambiente formador especifico que é modificado e reconstruído a partir de estruturas de funcionamento próprias.

Mas Gomez (2001) introduz elementos novos para esta análise, o mais importante deles é o de que a escola é entrecruzada por diversos tipos de culturas. ${ }^{4}$ Nesse sentido, o que está em jogo é a apreensão do processo de reprodução da função social da escola pela própria instituição educacional, assim como a simbiose conflitiva de encontro de diversos tipos de produção de semiótica. Gomes considera a escola

\footnotetext{
4 "Considero cultura como o conjunto de significados, expectativas e comportamentos compartilhados por um determinado grupo social, o qual facilita e ordena, limita e potencia os intercâmbios sociais, as produções simbólicas e materiais e as realizações individuais e coletivas dentro de um marco espacial e temporal determinado. A cultura, portanto, é o resultado da construção social, contingente às condições materiais, sociais e espirituais que dominam um espaço e um tempo. Expressa-se em significados, valores, sentimentos, costumes, rituais, instituições e objetos, sentimentos (materiais e simbólicos) que circundam a vida individual e coletiva da comunidade" (GOMES, 2001. pp.17).
}

Revista Tópicos Educacionais, Pernambuco, v. 27, n. 01, p. 195-209, 2021. ISSN: 2448-0215.

https://periodicos.ufpe.br/revistas/topicoseducacionais/index 
como um espaço ecológico de cruzamento de culturas, cuja responsabilidade específica, que a distingue de outras instituições e instâncias de socialização e lhe confere sua própria identidade e sua relativa autonomia, é a mediação reflexiva daqueles influxos plurais que as diferentes culturas exercem de forma permanente sobre as novas gerações, para facilitar seu desenvolvimento educativo. (GOMEZ, 2001.p.17)

Mas quais culturas são essas que o autor se refere? Para Gomes (2001) a escola produz e busca conservar condicionantes de vivência institucionalizados e rituais que somente ela pode produzir. Esses condicionantes dizem respeito à sua rotina, ao locus formador de estruturas que é o ambiente escolar. Por outro lado, essa instituição e suas relações sociais intrínsecas são inteiramente influenciadas pelas políticas de desenvolvimento profissional, pela cultura docente e a organização escolar (GOMES, 2001). Esses fatores, apesar de serem desenvolvidos no âmbito governamental ou em suas ramificações (Secretarias, Diretorias escolares etc) alteram ou são alterados através dos intercâmbios que ocorrem dentro desta instituição:

A análise do que realmente acontece na escola e dos efeitos que tem nos pensamentos, nos sentimentos e nas condutas dos estudantes requer descer aos intercâmbios subterrâneos de significados que se reproduzem nos momentos e nas situações mais diversas e inadverditas da vida cotidiana da escola. As diferentes culturas que se entrecruzam no espaço escolar impregnam o sentido dos intercâmbios e o valor das transações em meio às quais se desenvolve e construção de significados de cada individuo (GOMEZ, 2001. p 17).

Esse campo também é afetado pelo conteúdo acadêmico, o qual é legitimado como um dos cabedais específicos da instituição escolar, delimitando e criando linhas tênues a partir das quais os conteúdos que mediam a relação professor-educando não ultrapassam sem pelo menos um dos envolvidos transgrida a rotina pré-estabelecida. Como ambiente científico, a escola é o local onde o acumulo de conhecimento da humanidade deve ser utilizado como ponto de partida, e não de chegada, para novos questionamentos e paradigmas (GOMES, 2001, p. 259). Para o autor, o currículo acadêmico é composto pelos conteúdos selecionados externamente à escola, mas também há aquele que é construído conjuntamente com os educandos. Esse currículo coloca um problema fundamental, que é o fato de que a escola é uma entidade artificial distanciada da vida, a qual tem como um dos objetivos realizar a aprendizagem relevante, cujos conteúdos não se relacionam abstratamente com os intercâmbios da vida cotidiana. 
A cultura escolar também seria constituída por uma cultura experiencial configurada pela construção de significados e comportamento a partir da indução que o próprio contexto educacional favorece acrescida dos

intercâmbios espontâneos com o meio familiar e social que rodeiam sua existência. A cultura do estudante é o reflexo da cultura social de sua comunidade, mediatizada por sua experiência biográfica, estreitamente vinculada ao contexto. A cultura experiencial do individuo é o reflexo incipiente de uma cultura local, construída a partir de aproximações empíricas e aceitações sem elaborar criticamente (GOMES, 2001, p. 205).

Essa cultura experiencial seria de suma importância para a constituição do universo escolar, pois ela traria conhecimentos práticos e abstratos adquiridos que inevitavelmente confrontar-se-iam com os conhecimentos repassados para a instituição escolar.

Em sua tipologia de culturas o autor indica que há uma cultura social que, mais abrangente que as citadas anteriormente, contribui para a composição da cultura escolar. O autor partiu da produção de semiótica no contexto escolar através da cultura institucional, depois para o acumulo experiencial dos educandos para logo em seguida considerar a reprodução macroestrutural de significados e comportamentos que trazendo formas de comportamento e significados hegemônicos da realidade contemporânea globalizada teriam como duas principais características: serem veiculados pelos meios de comunicação de massa e serem "regidas pelas leis do livre mercado" (GOMES, 2001, p. 84).

Deriva dessa noção de lógica do livre mercado transmitida pela globalização os efeitos para a vida social. Algumas das patologias sinalizadas é o consumo de massa e a democracia limitada (GOMES, 2001, p. 86). O panorama revela a cultura social como reflexo da crise da pósmodernidade. A crise produziu, segundo Gomes (2001), efeitos na psique das novas gerações. Ele enfatiza o papel dos meios de comunicação de massa na veiculação de novos valores e hábitos, fragilizados pela inconstância e perenidade. O processo da socialização na época pós-moderna seria derivado da lógica do livre mercado globalizado com todas suas consequências para as relações sociais. Nela há uma obsessão pela eficiência, tornando rentáveis instituições que produzem resultados em sua grande parte não mensuráveis, como a escola e a universidade. Nesse mundo fragmentado tudo é perene, os fatos são ahistóricos, as mudanças são efêmeras e a sociedade funciona cada vez mais em torno da imagem, da informação e de um hedonismo insustentável.

É interessante relacionar essas ideias com o fato de que nos últimos decênios tem-se visto uma dilaceração de grandes obras literárias com o fim de tornarem-se acessíveis à leitura para Revista Tópicos Educacionais, Pernambuco, v. 27, n. 01, p. 195-209, 2021. ISSN: 2448-0215. https://periodicos.ufpe.br/revistas/topicoseducacionais/index DOI: 10.51359/2448-0215.2021.249424 
crianças e adolescentes. A escassez de tempo, substancialidade e qualidade são sintomas que indicam a lógica do capital como contexto das transformações culturais decorrentes da expansão da acumulação dele. Gomes (2001) pode contribuir para o avanço da perspectiva de que a cultura escolar é atravessada por diversos outros tipos de culturas, mas mesmo de forma não explicita não coaduna com toda uma bibliografia que visualiza todas as relações sociais interpassadas pela lógica do capital, que não obstante, subtrai a produção de alienação, ${ }^{5}$ privando os trabalhadores da produção de si mesmos, tornando as mercadorias meras matérias abortivas da subjetividade de uns poucos trabalhadores especializados. O capital transforma tudo em mercadoria, inclusive o que antes era presumivelmente irrentável como a água, o ar, o nascimento, a morte e os sentimentos. O poeta Bertold Brecht sabia desse aspecto do capitalismo quando escreveu em

privatizaram sua vida, seu trabalho, sua hora de amar e seu direito de pensar. É da empresa privada o seu passo em frente, seu pão e seu salário. E agora não contente querem privatizar o conhecimento, a sabedoria, o pensamento, que só à humanidade pertence.

Guattari (2000) também entendeu que as consequências da produção de mercadorias atingem todos os âmbitos da existência, para tudo que produz semiótica. Mas o autor vai além, entende que o movimento de produção capitalístico ${ }^{6}$ torna mercadorias também modos de andar, de se relacionar, de apresentar telejornais, de cumprimentar os colegas de trabalho etc. Nesse modo de produção de subjetividades, tudo pode ser resgatado para tornar-se mercadoria, ou seja, ser serializado, modelado e registrado. Para Guattari (2000) os indivíduos estão sujeitos a diversos mecanismos de agenciamentos de subjetividade, mas há um mais amplo que o autor intitula produção de subjetividade capitalística (GUATTARI, 2000).

\footnotetext{
5 "Temos que, já de início, sublinhar que, na obra de Marx, diferentemente da forma trabalhada e consagrada pela bibliografia que tratou do tema, existe uma distinção entre alienação (Entäusserung) e estranhamento (Entfremdung): enquanto alienação tem o significado de algo ineliminável do homem, uma exteriorização que o autoproduz e forma no interior de sua sociabilidade, estranhamento é designação para as insuficiências de realização do gênero humano decorrentes das formas históricas de apropriação do trabalho, incluindo a própria personalidade humana, assim como as condições objetivas engendradas pela produção e reprodução do homem." In RANIERI, Jesus. Alienação e estranhamento: a atualidade de Marx na crítica contemporânea do capital in https://www.nodo50.org/cubasigloXXI/congreso06/conf3_ranieri.pdf

${ }^{6} \mathrm{O}$ autor utiliza esse termo para diferenciar o conceito de produção capitalista dos autores marxistas. Para Guattari o modo de produção capitalístico vai além da produção de mercadorias e consequentemente das implicações que este termo traz para a análise das relações sociais. A produção de subjetividade através do atravessamento do capitalismo em todos os âmbitos da existência permite ao autor fundar esse outro termo que indica seu entendimento que a estruturação do modus viventis é constituído pela conformação dos corpos, gestos, hábitos, modos de se vestir, de andar de colher, pelo produção de significados que o capitalismo traz e que são subjetivados pelos diversos modos de proliferação dessa semiótica.
} 
Portanto, a escola seria apenas mais umas das instituições perpassadas pelo movimento de produção capitalístico. Mas ao considerarmos a escola como um espaço público onde a ascensão social e a socialização seriam as duas principais funções teremos que tomar como fatores de suma importância quais mecanismos podem produzir transgressões àquele movimento capitalístico e quais favorecem a reprodução de subjetividades capitalísticas, que aliadas aos padrões sociais de seleção, podem ajudar a manutenção do status quo intra e extra escolar, se é que ainda podemos fazer essa separação.

Aqui, a exploração do conceito de habitus de Bourdieu (2007) faria com que avançássemos na leitura da escola como espaço estrutural estruturante. Em outras palavras, a partir de funções e mecanismos particulares faria com que a cultura experiencial citada por Gomes (2001) encontrasse no contexto escolar uma estrutura de reprodução de habitus que privilegiaria os educandos possuidores de maior capital cultural. Aqui residiria uma das principais especificidades da instituição escolar que serve como órgão selecionador de indivíduos com maior capital cultural. O sistema escolar funciona de modo a classificar aqueles de detém capitais culturais desiguais. Sendo o capital cultural herdado principalmente do seio familiar, essa seleção não deixa de manter também as desigualdades sociais, pois está estreitamente ligado à quantidade de capital econômico:

(...) ele (o sistema escolar) produz efeitos dos quais não poderemos dar conta a não ser abandonando a (perigosa) linguagem mecânica. Instaurando uma ruptura entre os alunos das faculdades, a instituição escolar institui fronteiras sociais análogas àquelas que separavam a grande nobreza da pequena nobreza, e esta dos simples plebeus (BOURDIEU, 2007. p. 36)

Esses efeitos são frutos das disposições que os indivíduos a partir das quais geram e reproduzem habitus, que como externalizações daquelas disposições irão contribuir para a desigualdade de capital cultural e assim a reproduzir o status quo. Veremos a seguir como os habitus são geridos e quais suas conseqüências para o objeto aqui estudado, que é a suposta especificidade da cultura escolar em relação das demais.

\section{O CONCEITO DE HABITUS EM PIERRE BOURDIEU}


O conceito de habitus se refere à capacidade de uma estrutura social ser interiorizada pelos indivíduos e ser reproduzida através de práticas culturais. Ele é

esse principio gerador e unificador que retraduz as características intrínsecas e relacionais de uma posição em um estilo de vida unívoco, isto é, em um conjunto de escolas, de pessoas, de bens, de práticas (BOURDIEU, 2007, p. 22).

Bourdieu afirma que no ambiente escolar há estruturas que criam e reproduzem práticas e representações que podem tornar-se regras a partir de certa regularidade dessas ações que fixam esquemas funcionais os quais resolveram problemas em experiências anteriores e que se tornam referências de apreciações, gestos, percepções e ações. Dessa forma, tornam-se práticas coletivas reproduzidas sem que seus próprios executores tenham total consciência desse mecanismo (BOURDIEU, 2007). Sendo a realidade relacional, o habitus é uma posição num sistema disposicional onde modos de existência levam a determinadas formas de agir, pensar, andar, ouvir música, etc. No entanto, essas disposições não são deterministas. Elas permitem o agir sem pensar. São ações inconscientes que somente podem ser esclarecidas se observadas e analisadas pelo investigador, que as classifica a partir da realidade fazendo recortes metodológicos com o fim de que as ações não sejam mais vistas como atos desinteressados ou interessados per si, mas localizados em uma estrutura que permite a flexibilização e a elasticidade das ações.

Bourdieu (2006), em seu artigo intitulado O camponês e seu corpo (1962) faz um estudo sobre a interiorização de costumes pelos camponeses de uma cidade no interior da França. $\mathrm{O}$ autor descreve como esses costumes são externalizados através das expressões de seus corpos nas festas em que frequentam, onde são introvertidos, inseguros e se acham inferiores. Diferentemente dos citadinos que conseguem relacionar-se mais facilmente com as camponesas porque são mais despojados, seus corpos são soltos, dançam de forma mais desinibida. O autor pretende também mostrar um choque cultural entre o campo e a cidade e a consequência das trocas que são produzidas entre eles. Essa pesquisa é importante para entendermos como a interiorização de costumes através das relações sociais pode causar transformações na estrutura da família e na dinâmica da sociedade (BOURDIEU, 2006).

O habitus é uma espécie de regra do jogo cujos jogadores não sabem ou pelos menos não atentam que estão jogando. $\mathrm{O}$ conceito de habitus somente pode ser entendido se considerarmos o 
indivíduo como participante de uma racionalidade prática compartilhada por um grupo de pessoas que detém graus muitos próximos de capital cultural e econômico. Como afirmamos anteriormente, para Bourdieu (2006) a disposição de cada um desses capitais dentro do capital geral é mais importante do que a quantidade de cada um isoladamente quando buscamos entender a configuração da estruturação da estruturação de organizações de ações (BOURDIEU, 2006, p. 48).

Essa categoria de Bourdieu (2006) pode ser entendida também como uma segunda natureza, que diferentemente da primeira, instintiva, que seria a mesma em todos os seres humanos, a ultima diferencia-os entre si e é construída historicamente e permite ao individuo agir em seu meio ambiente de modo que seus atos, suas falas, seu pensamento façam sentido dentro da trama de significados (BOURDIEU, 2006, p. 48). Seu modo de agir é intencional, mas provém de uma intencionalidade inconsciente. Bourdieu (2006) critica os teóricos que supõem o ser humano como calculista e praticante racional de ações autodeterminadas para conseguirem o maior lucro possível. As teorias que buscam a explicação da origem das ações através da categoria homus economicus não coadunam com ponto de vista de Bourdieu (2006) porque para este as intenções são aprendidas através das diversas instituições que compõem a trama de significados disponíveis para a construção do processo de socialização.

Mas os habitus são não apenas resultados de estruturas e/ou disposições que reproduzem práticas, são também geradores de formas de existência, modo de agir, falar, andar. Eles reproduzem e são reproduzidos (Bourdieu,1980, p. 88). São estruturas estruturadas estruturantes, ou seja, são condicionadas e condicionantes.

\section{PÉREZ-GÓMES, PIERRE BOURDIEU E FÉLIX GUATTARI: APROXIMAÇÃO A PARTIR DO CONCEITO DE CULTURA ESCOLAR}

Gomes (2001) é um dos muitos autores que setorializam tipos de cultura para utilizar eles como pressupostos analíticos. Como vimos, o autor entende que a escola tem a função de mediação de diferentes tipos de cultura, tais como a cultura critica, a cultura social, a cultura institucional, a cultura experiencial e a cultura acadêmica. Para esse autor, esses diversos tipos de cultura são mediados no processo de escolarização e os envolvidos nesse processo são produtores e asujeitados de elementos dessa cultura (GOMES, 2001). 


\section{Revista Tópicos Educacionais}

Guattari (1997), no entanto, questiona o conceito de cultura e de identidade cultural afirmando que eles são reacionários porque segmentam níveis de subjetividade, classificando metodologicamente as múltiplas facetas das relações dentro dos grupos sociais. Estes conceitos tendem a solidificar características de subjetivação que estão sempre em pleno processo de criação, formando com isso uma personalidade de base, um modo correto de executar rituais, de se vestir, etc (GUATTARI, 1977). Guattari (1997) entende que a desvinculação dos grupos de minorias a uma ótica que entende as relações sociais interligadas e atravessadas por processos de produção capitalísticos tem consequências políticas importantes. Ao reificar a identidade cultural, esses grupos deixam de dar espaço suficiente para o desenvolvimento do processo de singularização, tornando-se normalizados e enquadrados, não apresentando novas formas de existência que poderiam contrapor a subjetividade capitalística.

Para Guattari (2000), o conceito de cultura e o de identidade cultural direcionam em si o resultado das análises sobre os contextos sociais específicos. Setorializam o modo de autoprodução da existência, trazem algo tão falacioso quanto afirmar que existem modos de produção de mercadorias desprovidos de produção de subjetividade capitalística: “no fundo, só há uma cultura: a capitalística. É uma cultura sempre etnocêntrica e intelectocêntrica (ou logocêntrica), pois separa os universos semióticos das produções subjetivas" (GUATTARI, 2000, p. 30).

Umas das dificuldades em investigar a construção da trama de significados na e para a escola reside na acepção que muitos autores têm em suas metodologias de que o econômico colonizaria o terreno cultural ou ao contrário, que bastaria focos de resistência através de métodos pedagógicos, em uma mudança de práxis repentina que toda a estrutura social sucumbiria. Entende-se que a relação entre a estrutura econômica, ou seja, as forças produtivas e seus tipos de relações sociais, de acordo com os modos de produção e a noção de superestrutura, que seria constituída pela forma do Estado, ideologia hegemônica e contra hegemônica, é dialético- histórica. A realidade e sua complexidade exigem que o investigador "se situe em uma perspectiva que utiliza melhor o capital de conceitos, métodos, de técnicas acumulado por seus predecessores" (Bourdieu, 2006. p. 35). Por isso, as noções de cultura não podem ser reduzidas à produtos da estruturas através do desenvolvimento das forças produtivas e das relações de produção.

O processo de produção de subjetivação capitalístico não isenta as culturas citadas por Gomes (2001) de submeterem os educandos no processo de escolarização à criação de valores produtivos dentro do sistema capitalista. Em outras palavras, eles são também mercadorias desse ponto de vista, já que o sistema capitalístico busca a expansão de signos, modos de articular o pensamento, a meritocracia, Revista Tópicos Educacionais, Pernambuco, v. 27, n. 01, p. 195-209, 2021. ISSN: 2448-0215. https://periodicos.ufpe.br/revistas/topicoseducacionais/index DOI: $10.51359 / 2448-0215.2021 .249424$ 
a premiação, o gosto pela competitividade, o utilitarismo, a perversão da busca de ascensão social quando aliada a uma alienação estéril dos processos de criação, tanto através da educação bancária ${ }^{7}$ quanto em uma educação humanista setorial, desenvolvida apenas em algumas disciplinas, como a Sociologia, a História e a Geografia.

Bourdieu (1996) entende essa relação entre a escola e o capitalismo com outras ferramentas metodológicas. A relação entre a família, o educando e a escola é afetada diretamente de acordo com a quantidade e disposição do capital cultural e do capital econômico. A família tende a se reproduzir, mas seu investimento na educação escolar varia tanto quanto aqueles dois tipos de capital. As famílias

investem tanto mais na educação escolar (...) quanto mais importante for seu capital cultural e quanto maior for o peso relativo de seu capital cultural em relação ao seu capital econômico e, também , quanto menos eficazes forem as outras estratégias de reprodução, particularmente, as estratégias de herança que visam à transmissão direta do capital econômico) ou relativamente menos rentáveis (BOURDIEU, 1996. p. 36).

O habitus adquirido pela herança cultural da família favorece a manutenção dos mecanismos de seleção dos educandos bem sucedidos. O processo de seleção teria a escola como instituição participante na valorização do capital cultural, que aliado ao capital econômico faz perpetuar uma estrutura de funcionamento. Essa estrutura pode ser chamada de cultura? Esse mecanismo citado pode ser entendido como parte de um processo global que favorece a desigualdade na distribuição de capital cultural e capital econômico. Essa desigualdade perpassa todos os âmbitos sociais, se entendermos a realidade como um sistema onde a trama de significados é construída e reconstruída pelos indivíduos, pois nenhum deles está dispensado do processo de produção capitalístico. Portanto, podem considerar que essas estruturas de funcionamento fazem parte de uma cultura capitalística que busca a valorização do capital em todos os âmbitos da vida.

Esse conceito de Guattari (2000) tem a vantagem de não separar metodologicamente o processo de produção de mercadorias do processo de produção da existência em todos seus aspectos, no falar, no vestir, no andar. A superestrutura está envolvida na estrutura. Esses conceitos gastos pelo uso, pelo mal uso e por suas insuficiências no estudo da realidade não podem responder mais aos ímpetos analíticos se considerarmos que o modo que profissionais da mídia falam e apresentam telejornais, também são mercadorias.

7 Esse termo foi criado por Paulo Freire em Pedagogia do Oprimido (1974)

Revista Tópicos Educacionais, Pernambuco, v. 27, n. 01, p. 195-209, 2021. ISSN: 2448-0215.

https://periodicos.ufpe.br/revistas/topicoseducacionais/index 


\section{Referências}

ALTHUSSER, L. P. Aparelhos Ideológicos de Estado. 7ª ed. Rio de Janeiro: Graal, 1998.

BOURDIEU, PIERRE. ESCRITOS DE EDUCAÇÃO. EDITORA VOZES. PETRÓPOLIS. RIO DE JANEIRO.2007. . RAZÕES PRÁTICAS. SOBRE A TEORIA DA AÇÃO. $8^{\circ}$ EDIÇÃO. TRADUÇÃO

MARIZA CORREAA. PAPIRUS EDITORA. CAMPINAS-SP, 1996.

CANDIDO, ANTONIO. A ESTRUTURA DA ESCOLA. IN: PEREIRA, LUIZ; FORACCHI, MARIALICE M. EDUCAÇÃO E SOCIEDADE. 6. ED. SÃO PAULO: EDITORA NACIONAL, 1971.

DAYRELL, J. A ESCOLA COMO ESPAÇO SOCIOCULTURAL. IN: DAYRELL, J. (ORG.). MÚLTIPLOS OLHARES SOBRE EDUCAÇÃO E CULTURA. BELO HORIZONTE: UFMG, 1996.

EAGLETON, TERRY. A IDÉIA DE CULTURA. TRADUÇÃO SANDRA CASTELLO BRANCO. EDITORA UNESP. SÃO PAULO, 2005.

FOUCAULT, Michel. Microfísica do Poder. eda'16. Rio de Janeiro: Graal. 2001.

GEERTZ, CLIFFORD. A INTERPRETAÇÃO DAS CULTURAS. L.ED., IS.REIMPR. - RIO DE JANEIRO :LTC, 2008

GÓMEZ, PÉREZ. A CULTURA ESCOLAR NA SOCIEDADE NEOLIBERAL. PORTO ALEGRE: ARTMED, 2001.

GUATTARI, Félix; ROLNIK, Suely. Micropolítica: cartografias do desejo. 6. ed. Petrópolis: Editora Vozes, 2000. LÉVI-STRAUSS, C. "Raça e História" in Antropologia Estrutural II Rio de Janeiro: Tempo Brasileiro, 1976, capítulo XVIII, pp 328-366.

Recebido em janeiro de 2021.

Aprovado em junho de 2021.

Revista Tópicos Educacionais, Pernambuco, v. 27, n. 01, p. 195-209, 2021. ISSN: 2448-0215.

https://periodicos.ufpe.br/revistas/topicoseducacionais/index 